\begin{tabular}{|l|c|}
\hline KeB UnMUL & K I N E R J A 15 (1), 2018 14-20 \\
http://journal.feb.unmul.ac.id/index.php/KINERJA
\end{tabular}

\title{
Dampak krisis dan kinerja keuangan terhadap loan loss provision
}

\author{
Nurul Hamisyah' ${ }^{1}$, Djoko Setyadi², Rizky Yudaruddin ${ }^{3}$ \\ Fakultas Ekonomi dan Bisnis, Universitas Mulawarman, Samarinda. \\ ${ }^{1}$ Email: Nurulhamisyah997@gmail.com \\ ${ }^{2}$ Email: djoko.setyadi@feb.unmul.ac.id \\ ${ }^{3}$ Email: rizky.yudaruddin@feb.unmul.ac.id
}

\begin{abstract}
Abstrak
Tujuan dari penelitian ini adalah untuk melihat bagaimana dampak Krisis dan Kinerja Keuangan Terhadap Loan Loss Provision pada tahun 2008-2015. Data diperoleh dari Laporan Keuangan publikasi yand diterbitkan Bank Indonesia dengan periode waktu tahun 2008 hingga 2015. Jumlah populasi dalam penelitian ini adalah 26 Bank Pembangunan Daerah dengan melewati tahap purposive sampling. Penelitian ini menggunakan regresi data panel dengan metode Random Effect Method (REM) melalui program Eviews 8. Hasil dari penelitian ini menunjukkan bahwa pengaruh Earning Before Taxes and Provision positif dan tidak signifikan terhadap Loan Loss Provision, kemudian Market Lending Rate berpengaruh negatif dan signifikan terhadap Loan Loss Provision, sedangkan Equity Ratio berpengaruh negatif dan signifikan terhadap Loan Loss Provision, Non-Interest Income to Assets berpengaruh negatif dan signifikan terhadap Loan Loss Provision, dan Krisis berpengaruh negatif dan signifikan terhadap Loan Loss Provision Bank di Indonesia.
\end{abstract}

Kata Kunci: penghasilan sebelum pajak; suku bunga pinjaman pasar; rasio ekuitas; pendapatan non-bunga; krisis

\section{Dampak krisis dan kinerja keuangan terhadap loan loss provision}

\begin{abstract}
The purpose of this study is to see how the impact of Crisis and Financial Performance on Loan Loss Provision in 2008-2015. The data is obtained from the published publication report published by Bank Indonesia with the period of 2008 to 2015. The total population in this study is 26 Regional Development Banks by passing through the purposive sampling stage. This research uses panel data regression with Random Effect Method (REM) through Eviews 8 program. The results of this study indicate that the influence of Earning Before Taxes and Provision is positive and not significant to Loan Loss Provision, then Market Lending Rate has a negative and significant effect on Loan Loss Provision, While Equity Ratio has a negative and significant effect on Loan Loss Provision, Non-Interest Income to Assets has a negative and significant effect on Loan Loss Provision, and Crisis has a negative and significant effect on Loan Loss Provision Bank in Indonesia.
\end{abstract}

Keywords: earning before taxes and provision; market lending rate; equity ratio; non-interest income; crisis 


\section{PENDAHULUAN}

Bank termasuk lembaga keuangan yang sangat penting peranannya dalam pembangunan ekonomi. Peran strategis bank bukan hanya sebagai wahana yang mampu menghimpun dan menyalurkan dana masyarakat secara efektif dan efisien kearah peningkatan taraf hidup masyarakat, akan tetapi juga memotivasi dan mendorong inovasi dalam berbagai cabang kegiatan ekonomi. Juga merupakan suatu lembaga yang mampu dipercaya oleh masyarakat golongan manapun, digunakan untuk berbagai macam transaksi yang berhubungan dengan keuangan, dan bank juga sangat mempengaruhi kemajuan suatu negaranya.

Bank juga sebagai lembaga intermediasi memiliki kegiatan inti yaitu menghimpun dana dari masyarakat yang memiliki kelebihan dana dan menyalurkan kembali kepada masyarakat yang membutuhkan, fungsi ini yang biasa disebut dengan intermediasi. Menyalurkan dana kepada masyarakat dalam bentuk kredit memiliki risiko kerugian bagi bank, risiko ini muncul jika debitur tidak dapat membayarkan kewajibannya kepada bank karena suatu alasan tertentu. Untuk mengantisipasi risiko tersebut bank diwajibkan membentuk dan menyisihkan dana untuk menutup risiko kerugian terhadap kredit yang diberikan kepada nasabah.

Loan Loss Provisions (LLP) atau di Indonesia lebih dikenal dengan istilah PPAP menjadi isu yang menarik karena dijadikan dasar pengambilan keputusan yang berkaitan dengan penggantian manajemen. Penyisihan penghapusan aktiva produktif (PPAP) menjadi pos yang menggambarkan perilaku manajemen baru dalam mengelola jumlah setiap kelompok kualitas aktiva produktif. Pertama, aktiva produkif yang sebenarnya digolongkan "macet" dapat digolongkan "diragukan" atau "kurang lancar" sehingga berdampak pada jumlah penyisihan penghapusan aktiva produktif (PPAP) yang harus dibentuk menjadi lebih rendah. Kedua, manajemenbaru sengaja menurunkan golongan aktiva produktifnya darikelompok sebenarnya untuk tahun berjalan agar pada tahun selanjutnya tidakperlu melakukan penyesuaian yang berarti dan berharap terjadi pembalikan (kebalikan dari penyisihan yang akhirnya menjadi pendapatan) untuk mencapai kinerja yang cemerlangdi masa kepemimpinan manajemen baru (Retnadi, 2006).

Loan Loss Provision berfungsi sebagai cadangan umum dan cadangan khusus untuk menutupi risiko yang terjadi karena adanya kegiatan kredit dan untuk menjaga kestabilan keuangan bank agar tetap likuid. Didalam LLP pembentukan atau penyisihan dana dinilai dari hasil evaluasi kredit debitur yang dilakukan oleh masing-masing bank. Jika menurut suatu bank terdapat bukti objektif bahwa kredit dari debitur itu mengalami impairment (penurunan), maka bank itu harus membentuk dana yang akan digunakan sebagai cadangan atas kredit tersebut.

\section{Kajian Pustaka \\ Pengertian Bank}

Pengertian bank menurut Undang-Undang RI Nomor 10 Tahun 1998 Tanggal 10 November 1998 tentang perbankan adalah Badan usaha yang menghimpun dana dari masyarakat dalam bentuk simpanan dan menyalurkan kepada masyarakat dalam bentuk kredit dan atau bentuk-bentuk lainnya dalam rangka meningkatkan taraf hidup rakyat banyak.

\section{Fungsi Bank}

Bank sebagai badan usaha yang bank bergerak dibidang jasa keuangan memiliki fungsi utama (kuncoro dan Suhardjono, $2002: 68-69$ ) yaitu :

Bank sebagai lembaga yang menghimpun dan masyarakat dalam bentuk simpanan; Bank sebagai lembaga yang menyalurkan dana ke masyarakat dalam bantuk kredit; Bank sebagai lambaga yang melancarkan transaksi perdagangan dan peredaran uang.

\section{Jenis Bank}

Jenis bank dapat dikelompokkan berdasarkan:

Fungsinya; Kepemilikan; Status; Cara Menentukan Harga;

\section{Kredit}

Bank sebagai badan usaha yang bank bergerak dibidang jasa keuangan memiliki fungsi utama (kuncoro dan Suhardjono, 2002 :68-69) yaitu :Menurut Kasmir (2001:72) Kredit berasal dari bahasa Yunani Credere yang berarti kepercayaan atau dalam bahasa latin Creditum yang berarti kepercayaan 
akan kebenaran, Berdasarkan Undang-undang Nomor 10 Tahun1998, kredit adalah penyedian uang atau tagihan yang dipersamakan dengan itu, berdasarkan persetujuan atau kesepakatan pinjam-meminjam antara bank dengan pihak lain yang diwajibkan pihak peminjam untuk melunasi hutangnya setelahjangka waktu tertentu dengan jumlah bunga.

\section{METODE}

Penelitian ini menggunakan pendekatan kuantitatif yang merupakan metode pengumpulan data sekunder yang diperoleh dalam bentuk laporan sudah jadi, yaitu diolah dan disajikan oleh pihak lain. Data tersebut berupa jurnal penelitian, laporan keuangan bank 2008 hingga 2015. Populasi penelitian adalah seluruh Bank BPD di Indonesia. Banyaknya populasi tersebut yaitu sebanyak 26 bank yang tersebar di seluruh Indonesia. Data pada penelitian ini berasal dari laporan keuangan pada seluruh BPD di Indonesia periode Tahun 2008-2015. Untuk menentukan sampel dari penelitian ini, peneliti menggunakan metode purposive sampling. Metode purposive sampling adalah teknik sampling yang termasuk ke dalam kelompok nonprobability sampling. Nonprobability sampling adalah teknik penarikan sampel yang tidak memberikan kesempatan atau peluang yang sama bagi setiap anggota populasi untuk dipilih menjadi sampel. Model analisis yang digunakan berdasarkan pada regresi data panel yang disesuaikan dengan model weiss. Penggabungan data deret waktu dengan cross section disebut dengan data panel. Data panel adalah data yang diperoleh dari data cross section yang diobservasi berulang pada unit individu (objek) yang sama pada waktu yang berbeda.

\section{HASIL DAN PEMBAHASAN}

\section{Statistik Deskriptif}

Statistik deskriptif digunakan untuk melihat gambaran umum dari data yang digunakan. Dibawah ini merupakan tabel yang menunjukkan hasil statistic deskriptif atas variable-variabel yang ada pada permodelan data panel pada penelitian.

Tabel 1. Statistik Deskriptif variabel Loan Loss Provision,

\begin{tabular}{lcccccc}
\multicolumn{7}{c}{ EBTP, MLR, EQRATIO, NII dan KRISIS } \\
\hline Mean & 673087.5 & 356879.6 & 0.120393 & 6.800641 & 0.176242 & 0.250000 \\
Median & 98684.00 & 252798.5 & 0.114661 & 6.583333 & 0.140341 & 0.000000 \\
Maximum & 8387920. & 1747579. & 0.274967 & 7.550000 & 0.652878 & 1.000000 \\
Minimum & 5155.000 & 535.8320 & $7.87 \mathrm{E}-05$ & 5.770833 & 0.019431 & 0.000000 \\
Std. Dev. & 1496780. & 324443.9 & 0.035723 & 0.596012 & 0.119098 & 0.434057 \\
Observations & 208 & 208 & 208 & 208 & 208 & 208 \\
\hline Sum & & & & & & \\
\end{tabular}

Sumber: Data diolah tahun 2017

Berdasarkan hasil yang telah diolah dan telah di tunjukkan oleh tabel di atas dapat dilihat dan diketahui bahwa nilai LLP terendah ialah sebesar 5155.000, sedangkan nilai tertinggi adalah 8387920.. Nilai rata-rata dari variable LLP sebesar 673087.5, dengan standar deviasi sebesar 1496780.. Untuk variable EBTP memiliki nilai terendah dan tertinggi sebesar 535.8320 dan 1747579 . dengan nilai rata-rata sebesar 356879.6 dan standar deviasi sebesar 324443.9. Variabel MLR memiliki nilai tertinggi sebesar 0.274967 dan nilai terendah dari variable MLR sebesar 7.87E-05 dengan nilai rata-rata dan standar deviasi masing-masing sebesar 0.120393 dan 0.035723 . Pada variable EQRATIO memiliki nilai terendah dan tertinggi masing-masing sebesar 5.770833 dan 7.550000, nilai rata-rata dari variable EQRATIO 6.800641 dengan nilai standar deviasi sebesar 0.596012. Nilai rata-rata dari variable NII sebesar 0.176242 dan nilai terendah dan tertinggi dari variable NII masing-masing sebesar 0.019431 dan 0.652878 dengan nilai standar deviasi sebesar 0.119098. Nilai KRISIS memiliki standar deviasi sebesar 0.434057 , nilai rata-rata dari variable Krisis 0.250000 dan nilai tertinggi dan terendah dari variable krisis adalah 1.000000 dan 0.000000 . 


\section{Hasil Regresi}

Berdasarkan hasil analisis regresi data panel yang menggunakan alat bantu Eviews versi 8 diperoleh hasil sebagai berikut:

Tabel 2. Hasil Analisis Regresi Data Panel Variabel Loan Loss Provision EBTP, MLR, EQRATIO, NII DAN KRISIS

\begin{tabular}{lllllll}
\hline $\begin{array}{l}\text { Variabel } \\
\text { Terikat }\end{array}$ & $\begin{array}{l}\text { Variabel } \\
\text { Bebas }\end{array}$ & $\begin{array}{c}\text { Koefisien } \\
\text { Regresi }\end{array}$ & t hitung & Prob. & Arah & Ket. \\
& Konstanta & 3524588. & 3.642991 & 0.0003 & & \\
& EBTP & 0.495788 & 1.618921 & 0.1070 & + & Tdk signifikan \\
& MLR & -7233769. & -2.956129 & 0.0035 & - & Signifikan \\
$\begin{array}{l}\text { Loan Loss } \\
\text { Provision }\end{array}$ & EQRATIO & -459703.8 & -3.513107 & 0.0005 & - & Signifikan \\
& NII & 2458327 & 2.940929 & 0.0037 & - & Signifikan \\
& KRISIS & 2034394. & 9.930861 & 0.0000 & - & Signifikan \\
\hline $\begin{array}{l}\text { R-Square } \\
\text { Adjust R-Square }\end{array}$ & $: 0.385160$ & & & & \\
$\begin{array}{l}\text { F-Statistik } \\
\text { F Signifikan }\end{array}$ & $: 0.369941$ & & & & \\
\hline
\end{tabular}

Sumber: Data diolah tahun 2017

Berdasarkan hasil regresi yang telah di dapat. Seperti terlihat pada tabel 4.6 dapat dijelaskan uji hipotesis dalam penelitian ini adalah sebagai berikut:

\section{Koefisien Determinasi $\left(\mathrm{R}^{z}\right)$}

Koefisien determinasi pada intinya mengukur seberapa jauh kemampuan model dalam menerangkan variasi variabel dependen. Nilai R2 terletak antara 0 sampai dengan $1(0 \leq \mathrm{R} 2 \leq 1)$. Tujuan menghitung koefisien determinasi adalah untuk mengetahui pengaruh variabel independen terhadap variabel dependen. Hasil pengujian regresi data panel dengan menggunakan model REM menunjukkan nilai koefisien determinasi $\left(\mathrm{R}^{2}\right)$ dari model REM sebesar 0.385160 yang berarti variabel dependen (Loan Loss Provision) dapat dipengaruhi sebesar 38,51\% oleh variabel Independen (EBTP, MLR, EQRATIO, NII DAN KRISIS), sedangkan sisanya sebesar 61,49\% dijelaskan oleh variabel lain yang tidak terdapat dalam model penelitian ini.

\section{Uji Simultan (Uji F)}

Uji statistik F pada dasarnya menunjukkan apakah semua variabel independen yang dimasukkan dalam model mempunyai pengaruh secara bersama-sama atau simultan terhadap variabel dependen. Data pada Tabel 4.6. menunjukkan nilai F-statistik pada mode REM sebesar 25.30818. dengan nilai signifikansi (F signifikan) sebesar 0.000000 yang lebih kecil dari $0,05(0,0000<0,05)$. Hasil tersebut menjelaskan bahwa model regresi dapat digunakan untuk memprediksi tingkat LLP. Dengan kata lain bahwa dari kelima variabel independen yaitu EBTP, MLR, EQRATIO, NII DAN KRISIS secara bersamaan atau simultan berpengaruh terhadap Loan Loss Provision perbankan di Indonesia dan telah menunjukkan model yang layak atau yang baik untuk digunakan.

\section{Uji Parsial (Uji t)}

Uji hipotesis dilakukan untuk mengetahui ada atau tidaknya pengaruh yang signifikan antara variabel bebas: EBTP (X1), MLR (X2), EQRATIO (X3), NII (X4) dan Krisis (5) terhadap Loan Loss Provision (Y). Berdasarkan hasil pengujian regresi yang ditampilkan pada Tabel 4.6. diketahui bahwa variabel EBTP (X1) memiliki nilai t hitung sebesar 1.618921 dan tingkat probabilitas sebesar 0.1070 > 0,05 yang artinya bahwa secara parsial variabel EBTP berpengaruh positif dan tidak signifikan terhadap Loan Loss Provision. Variabel MLR (X2) memiliki nilai t hitung sebesar -2.956129 dengan nilai 
probabilitas sebesar $0.0035<0,01$ yang artinya bahwa secara parsial variabel MLR berpengaruh negatif signifikan terhadap Loan Loss Provision pada tingkat signifikan $1 \%$.

Variabel EQRATIO (X3) EQRATIO memiliki nilai t hitung sebesar -3.513107 dengan nilai probabilitas sebesar $0.0005<0,05$ yang artinya secara parsial variable EQRATIO berpengaruh negatif dan signifikan terhadap Loan Loss Provisio perbankan di Indonesia. Variabel NII (X4) NII memiliki nilai t hitung sebesar 2.940929 dengan nilai probabilitas masing-masing sebesar 0,0037 < 0,05 yang artinya secara parsial variabel NII berpengaruh negatif dan signifikan terhadap Loan Loss Provision. Variabel KRISIS (X5) memiliki nilai $t$ hitung sebesar 9.930861 dengan nilai probabilitas masing-masing sebesar 0,0000 $<0,05$ yang artinya secara parsial variabel KRISIS berpengaruh negatif dan signifikan terhadap Loan Loss Provision. Adapun model dari penelitian sebagai berikut:

Loan Loss Provision $=3524588 .+0.495788$ EBTP -7233769. MLR -459703.8

EQRATIO + 2458327 NII + 2034394. KRISIS

\section{HASIL DAN PEMBAHASAN}

\section{Pengaruh EBTP Terhadap LLP (Loan Loss Provision)}

Berdasarkan hasil Output regresi dengan menggunakan Eviews versi 8 diperoleh hasil bahwa Profitabilitas (EBTP) berpengaruh positif dan tidak signifikan terhadap LLP (Loan Loss Provision) perbankan di Indonesia. Hasil penelitian ini menunjukkan arah yang sama dengan penelitian Mismah dan Ahmad, 2011;, Dong et al. 2012;, Curcio dan Hasan, 2015;, Lim et al, 2013;, Forcesa dan Gonzalez, 2007; dan Pinho dan Martins, 2009. Namun, pendapat yang berbeda menurut Dinamona 2008 dan leaven dan Majnonni 2003 mengatakan bahwa bank-bank akan menciptakan lebih tinggi LLP ketika Bank-bank menderita kerugian atau negatif tingkat pendapatan sebelum ketentuan dan pajak,dan sebaliknya.

Hasil yang tidak signifikan disebabkan karena adanya beberapa bank yang menunjukkan pola yang berbeda dari teorinya dimana EBTP menurun maka akan mengakibatkan penurunan pada LLP perbankan di Indonesia. Sedang teorinya mengatakan bahwa apabila tingkat EBTP mengalami peningkatan maka akan mengakibatkan peningkatan juga terhadap LLP perbankan di Indonesia.

\section{Pengaruh MLR (Market Lending Rate) Terhadap LLP (Loan Loss Provision)}

Setelah dilakukan regresi menggunakan alat bantu eviews versi 8 diperoleh hasil MLR yang diproksikan dengan LLP berdampak negatif signifikan terhadap LLP. Hasil ini menunjukkan arah yang berbeda dengan penelitian. Hasil negatif pada LLP menunjukkan bahwa tidak sesuai dengan teori yang ada dalam peneitian ini. Hasil penelitiaan ini sejalan dengan penelitian yang di lakukan oleh Lim, et al. (2013). Namun hasil dari penelitian ini tidak sejalan dengan penelitian yang dilakukan oleh Glen dan Mondragon-Velez (2011) yang menyatakan bahwa ketika suku bunga pinjaman akan mempengaruhi kemampuan LLP untuk terus membayar bunga untuk pinjaman yang dipinjam. Ketika ekonomi tumbuh sehat, bank tidak akan mengharapkan penurunan abnormal pada kinerja mereka. Hal ini karena sebagian kecil dari penjaman akan kegagalan. Manun jika itu terjadi, peminjam tidak mampu membayar bunga pinjaman yang dipinjam, maka probabilitas gagal dalam peningkatan LLP.

\section{Pengaruh EQRATIO Terhadap LLP (Loan Loss Provision)}

Berdasarkan output yang telah diperoleh dari perhitungan mengunakan eviews versi 8 menunjukkan bahwa EQRATIO memiliki pengaruh negatif dan signifikan terhadap LLP. Hasil negatif pada EQRATIO menunjukkan bahwa semakin rendah EQRATIO bank di Indonesia maka akan meningkatkan tingkat LLP bank. Hasil ini sejalan dengan penelitian yang dilakukan oleh Kenagaretnam, et al. 2005;, Bouvater dan lepetit, 2008;, Anandarajan, et al, 2005; Leventis, et al. 2012;, dan Curcio dan Hasan, 2013. yang mengatakan bahwa semakin rendah tingkat modal bank, maka akan semakin ensintif untuk meningkatkan LLP bank tersebut namun penelitian ini tidak sejalan dengan penelitian yang dilakukan oleh Lim, et al. 2013 dan Abdullah, et al. 2014.

EQRATIO memainkan peran penting sebagai indicator status risiko bank. Hal ini menunjukkan kemampuan bank untuk bertahan hidup di bawah struktur modal saat ini dan menyiratkan risiko yang tak terlihat. Ketika rasio ekuitas meningkat, hal itu akan menyebabkan LLP bank menurun, dan semakin besar nilai rationya, maka semakin besar utang yang dimiliki oleh perusahaan. Artinya semakin besar kewajiban perusahaan yang harus dipenuhi kepada pihak lain. 


\section{Pengaruh NII Terhadap LLP (Loan Loss Provision)}

Hasil regresi yang didapat dari output eviews versi 8 memperlihatkan bahwa NII memberi pengaruh negative signifikan terhadap LLP bank di Indonesia. Hasil negatif dari NII menunjukkan bahwa NII memberi hasil yang ketidakpastian terhadap LLP. Ketika NII yang lebih tinggi maka cenderung membuat LLP menjadi ketidakefiesien. Hasil penelitian ini sejalan dengan penelitian Anandarajam, et al. 2005. Namun hasil berbeda dengan penelitian yang dilakukan oleh Yeh 2010. Hal ini disebabkan karena, ketika penentu dari LLP yang ketidakefiesiensi antara non-bunga yang lebih tinggi cenderung untuk ketidakefiesiensi LLP.

Dari hasil penelitian ini menunjukkan arah yang bebeda dengan teorinya namun hasil menunjukkan bahwa NII signifian terhadap LLP. Hal ini disebabkan adanya beberapa bank yang menunjukkan pola yang sama dari teorinya. Dimana ketika terjadi peningkatan atau lebih tinggi tinggkat beban NII maka cenderung untuk mengelola ketidaefiesiensi LLP pada bank tersebut. Misalnya pada BPD Sulawesi Tenggara di tahun 2010 dan BPD Papua di tahun 2012. Oleh karena itu, bank-bank dengan modal yang lebih tinggi tekanan rasio kurang dari regulator pemerintah dan dengan demikian lebih berdayaguna dalam pengambilan keputusan LLP.

\section{Pengaruh Krisis Terhadap LLP (Loan Loss Provision)}

Berdasarkan output yang telah diperoleh dari perhitungan menggunakan eviews versi 8 menunjukkan bahwa krisis berpengaruh negatif dan signifikan terhadap LLP (Loan Loss Provision). Hasil penelitian ini sesuai dengan teori Eng dan Nabar (2007) dimana berpengaruh negatif signifikan. Hasil negatif pada krisis ini menunjukkan bahwa ketika krisis pada sebuah bank naik maka LLP perbankan di Indonesia akan menurun.

Semakin tinggi tingkat krisis pada sebuah bank maka akan membuat cadangan menurun. Koefisien negatif pada krisis ini menunjukkan bahwa bank sampel menderita penurunan nilai LLP yang signfikan sebagai akibat dari krisis. Oleh karena itu, hasil yang negatif signifikan menunjukkan bahwa asosiasi antara ketentuan diskresioner dan return bank menurun selama krisis. Bank harus mengantisipasi keadaan suatu bank agar terhindar dari krisis.

\section{SIMPULAN}

Berdasarkan hasil penelitian yang telah dilakukan mengenai Earning Before Taxes and Provision, Market Lending Rate, Equity Ratio, Non-Interest Income to Assets dan KRISIS terhadap Loan Loss Provision Bank Pembangunan Daerah di Indonesia pada periode 2008-2015, maka dapat disimpulkan beberapa hal sebagai berikut:

Hasil dari pengujian hipotesis pertama menunjukkan bahwa pengaruh Earning Before Taxes and Provision positif dan tidak signifikan terhadap Loan Loss Provision bank di Indonesia. Dikarenakan hal ini tidak sesuai dengan teori arah yang sama tapi tidak signifikan karena ketika bank menerima pendapatan yang tingg, maka bank akan cenderung meningkatkan jumlah cadangan, dan sebaliknya.

Hasil dari hipotesis dua menunjukkan bahwa Market Lending Rate berpengaruh negatif dan signifikan terhadap Loan Loss Provision bank di Indonesia. Hal ini tidak sesuai dengan teori yang mengatakan bahwa ketika pihak peminjam berisiko rendah, mereka biasanya akan dikenakan tingkat bunga renda, dan sebaliknya.

Hasil dari hipotesis tiga yang menunjukkan bahwa Equity Ratio berpengaruh negatif dan signifikan terhadap Loan Loss Provision bank di Indonesia. semakin renda Equity Ratio bank maka akan meningkatkan tingkat Loan Loss Provision bank.

Hasil dari hipotesis empat yang menunjukkan bahwa Non-Interest Income to Assets berpengaruh negatif dan signifikan terhadap Loan Loss Provision bank di Indonesia. Berbeda dengan teori pada hipotesis penelitian ini. Ketika Non-Interest Income to Assets tinggi maka cenderung membuat Loan Loss Provision tidakpasti.

Hasil dari hipotesis lima yang menunjukkan bahwa Krisis berpengaruh negatif dan signifikan terhadap Loan Loss Provision bank di Indonesia. Hal ini sesuai dengan teori yaitu semakin Tinggi tingkat krisis pada sebuah bank maka Loan Loss Provision perbankan di Indonesia akan menurun. 


\section{DAFTAR PUSTAKA}

Anandarajan, A., Hasan, I., \& McCarthy, C. (2007). Use of loan loss provisions for capital, earnings management and signalling by Australian banks. Accounting and Finance, 47, 357-379.

Ahmed, A. S., Takeda, C., \& Thomas, S. (1999, November). Bank Loan Loss Provisions: A Reexamination of Capital Management, Earnings Management and Signaling Effects. Journal of Accounting and Economics, 28(1), 1-25.

Bikker, J., \& Metzemakers, P. (2004). Bank provisioning behaviour and procyclicality. Journal of International Financail Markets, Institutions \& Money, 15, 141-157.

Bouvatier, V., and L. Lepetit. 2006. "Banks' Procyclical Behavior: Does Provisioning Matter?” Journal of International Financial Markets, Institutions \& Money 18 (5): 513-526.

Eng, L. L., \& Nabar, S. (2007). Loan Loss Provisions by Banks in Hong Kong, Malaysia and Singapore. Journal of International Financial Management and Accounting, 18-38.

Fonseca, A. R., \& Gonzalez, F. (2007). Cross-country determinants of bank income smoothing by managing loan loss provisions.

Glen, J., \& Mondragon-Velez, C. (2011). Business Cycle Effects on Commercial Bank Loan Portfolio Performance in Developing Economies. Review of Development Finance, 1, 150-165.

Juanda, Bambang, dan Junaidi. 2012. Ekonomitra Deret Waktu Teori dan Aplikasi. Cetakan Pertama. IPB Pres. Bogor.

Kim, M.-S., \& Kross, W. (1998). The Impact of the 1989 Change in Bank Capital Standards on Loan Loss Provisions and Loan Write-Offs. Journal of Accounting and Economics, 25(1), 69-100.

Kuncoro, Mudrajad \& Suhardjono, 2002 , Manajemen Perbankan Teori \& Aplikasi. Edisi pertama, juli . dicetak \& diterbitkan oleh BPFF-Yogyakarta.

Kanagaretnam, K, GJ Lobo and R Mathieu (2004b). Earnings management to reduce earnings variability: Evidence from bank loan loss provisions. Review of Accounting and Finance, 3, $128-148$.

Leventis, S., P. E. Dimitropoulos, and A. Anandarajan. 2012. "Loan Loss Provisions,Earnings Management and Capital management under IFRS: The Case of EU Commercial Banks." Journal of Financial Services Research 40 (1-2):103-122.

Lim C. K., C. P. Yee., G. T. Mun Ee., T.S. Yean And W. K. Han (2013). "The determinants Of Bank Loan Provision In Malaysia." Bachelor Of Business Administration (Hons) Banking And Finance.

Misman, F. N., \& Ahmad, W. (2011, July). Loan Loss Provisions: Evidence from Malaysian Islamic and Conventional Banks. International Review of Business Research Papers, 7(4), 94-103.

Packer, F., \& Zhu, H. (2012). Loan Loss Provisioning Practices of Asian Banks. 1-27.

Pinho, P. S., \& Martins, N. C. (2009). Determinants of Portuguese Bank's Provisioning Policies: Discretionary Behaviour of Generic and Specific Allowances. Journal of Money, Investment and Banking(10), 43-56.

Smith \& Walter,. 2003, "Global Banking”. Second Edition. Oxford University Press.

Supriyanto. 2009. Metodologi Riset Bisnis, Indeks. Jakarta.

Widarjono, Agus. 2013. Ekonometrika Pengantar dan Aplikasinya. UPP STIM, YKPN. Yogyakarta.

Yeh, T.-1. (2010). Bank Loan Loss Provision Decisions: Empirical Analysis of Taiwanese Banks. Journal of Financial Services Marketing, 14(4), 278-289.

Zhou, Y.(2007, June). Bank Loan Loss Provisions and capital management under the basel accord. www.bi.go.id 